\title{
Intervenção Reflexiva: Instrumento de Formação Continuada do Educador Especial ${ }^{1}$
}

\author{
Lucia Pereira Leite \\ Maria Salete Fábio Aranha \\ Universidade Estadual Paulista - Bauru
}

\begin{abstract}
RESUMO - O presente artigo busca demonstrar a ocorrência de mudanças na prática pedagógica de uma professora, durante o período em que se fez a reflexão teórico-metodológica sobre essa prática, à luz de proposições da Psicologia sócio-histórica. Foram realizados 20 encontros reflexivos com uma professora da Educação Especial, a partir da análise de gravações das situações ocorridas em sala de aula. As discussões promovidas compreendiam aspectos relacionados ao processo de ensino e de aprendizagem na atividade docente. Foram examinadas as locuções verbais da professora e observaram-se indícios de mudança no que se refere ao foco de atenção, quando ela analisa seus problemas pedagógicos, na consideração da multideterminação dos problemas de ensino e aprendizagem, na concepção de aluno, no método de ensino, no estabelecimento e valorização da relação professor-aluno e da interação de alunos. Os resultados obtidos sinalizaram que a interação reflexiva mostrou-se um instrumento útil para a formação continuada de professores.
\end{abstract}

Palavras-chave: formação continuada; educação especial; intervenção reflexiva.

\section{Reflexive Intervention: Instrument of the Special Educator's Continued Formation}

\begin{abstract}
This study aims to identify the occurrence of changes in a teacher's pedagogical practice during a period when a reflection about this practice was done, based on theoretical propositions of social-historical Psychology. Twenty reflexive meetings were performed with a Special Education teacher aiming to propitiate the reflection of her pedagogical practice from the analysis of recordings of occurred situations in the classroom. The fostered discussions along this study were based theoretically on aspects related to the educational and learning process. The teacher's educational actions in the attempt to verify the occurrence of changes when she analyses her pedagogical problems regarding the multi-determination of the educational and learning problems, the student's conception, the educational method, the establishment and valorization of the teacher-student relation or students' interaction. The obtained results signalized that the reflexive interaction seems to be a useful instrument for the continued formation of teachers, indicating ways to their performance.
\end{abstract}

Key words: continued formation; special education; reflexive intervention.

Sabe-se que a educação brasileira tem historicamente vivenciado muitos problemas: um ensino elitista, de natureza excludente, que culpabiliza o aluno pela não aprendizagem, ao invés de focalizá-lo como o sujeito do direito que ele efetivamente é, partindo de suas peculiaridades individuais e de suas necessidades educacionais para elaborar e administrar o desenvolvimento do projeto pedagógico e do plano de ensino.

Tendo o país reconhecido essa situação e feito uma opção política formal pela universalização de um ensino que efetivamente disponibilize a todos o acesso ao conhecimento historicamente produzido e sistematizado pela humanidade, favorecendo as condições necessárias para a aprendizagem do exercício da cidadania, há que se investir no processo de

1 Este artigo deriva da tese intitulada "A Intervenção Reflexiva como Instrumento de Informação Contínuada do Educador: Um Estudo em Classe Especial”, defendida no Programa de Pós-Graduação em Educação na Universidade Estadual Paulista - Marília.

2 Endereço: Universidade Estadual Paulista, Av. Engenheiro Luiz Edmundo Carrijo Coube, Caixa Postal 473, Vargem Limpa, Bauru, SP, Brasil 17015-970. E-mail: lucialeite@fc.unesp.br educação continuada do professor, para que este possa desenvolver o conhecimento, as competências e as habilidades necessárias para o ensino na diversidade.

Vários autores têm desenvolvido estudos sobre o processo de educação continuada de professores, buscando identificar métodos eficazes para promover melhorias na prática educacional em sala de aula (Almeida, 1994; Aranha, 1998; Candau, 1996; Del Prette, Del Prette, Garcia \& Puntel, 1998; Fusari \& Rios, 1994; Leite, 1997; Prada, 2001; Zanotto, 2002). Na realidade internacional, a temática já vem sendo amplamente discutida e utilizada em pesquisas que objetivam estruturar formas de atendimento educacional que contemplem a permanência de todos os alunos na escola comum. Estudos realizados em Portugal e Espanha (Correa, 1999; García, 1999; Guijarro, 1992; Majón \& Gil \& Garrido, 1995; Oliveira, 1997; Sanchez, 1995; Schön, 1992; Ruiz \& Pereja, 2002) evidenciam, entre outros aspectos, que, ao se implementar situações reflexivas que possibilitem ao professor rever a sua prática pedagógica, ações educacionais são produzidas em sala de aula beneficiando o desenvolvimento de estruturas cognitivas dos alunos, a partir de um ensino 
pautado nas suas necessidades educacionais e no estabelecimento de processos interacionais entre pares diferenciados, alicerçando um ensino voltado para atender às respostas educacionais presentes na heterogeneidade das escolas. Destarte, a interação reflexiva sobre a prática pedagógica tem se caracterizado pela observação, análise e reflexão crítica conjunta, mostrando-se importante instrumento para a promoção de mudanças nos relatos e ações do professor, sob a mediação do pesquisador.

Este estudo vem dar continuidade a essa busca, apoiado na constatação da necessidade de se investir na formação continuada do professor, já que sua ação constitui elemento fundamental no processo de transformação do sistema educacional, visando à implementação de uma educação de qualidade para todos. Teve, então, por objetivo, identificar mudanças nos relatos do professor, quando submetido a um processo de reflexão teórico-metodológica sobre sua prática pedagógica, no decorrer de nove meses do ano letivo. Adotou-se a leitura sócio-histórica como fundamentação teórica para a compreensão sobre a atuação do professor, enquanto responsável pelo conjunto de ações que envolvem o processo de ensino e de aprendizagem.

Então, as concepções mostradas pelo professor, ou seja, o que ele pensa sobre os aspectos relatados acima, são de fundamental importância para a realização de sua prática profissional, sendo a observação, a análise, a reflexão conjunta e o repensar dos posicionamentos adotados, seus maiores instrumentos para efetivar a aprendizagem de seus alunos.

Este artigo, portanto, apresenta o estabelecimento de um processo interacional, dentro da Educação Especial, em que o pesquisador atuou como um observador externo, porém próximo ao desenrolar dos acontecimentos educacionais, acompanhando o cotidiano escolar e, finalmente, podendo promover discussões sobre a dinâmica do processo educacional.

\section{Método}

\section{Participante}

Professora formada em Pedagogia, com habilitação em Educação Especial, na área de Deficiência Mental, lotada em uma classe especial em escola estadual, em município do interior do Estado de São Paulo.

\section{Local}

Escola Estadual de Ensino Fundamental com atendimento a alunos com deficiência em quatro classes especiais, para a área de Deficiência Mental, e duas salas de recursos, para a de Deficiência Visual.Os componentes curriculares oferecidos na classe em que atuava a professora participante deste estudo eram os correspondentes aos da $1^{\mathrm{a}}$ série do ensino fundamental. Estavam matriculados nessa sala 12 alunos (10 com deficiência mental e dois com deficiência múltipla - deficiência mental associada à deficiência física). Desses alunos, sete tinham, em seu prontuário, um diagnóstico feito por psicóloga do serviço público de saúde, enquanto que os demais foram encaminhados por outra instituição, sem um diagnóstico formal.

\section{Material}

- Ofício de solicitação de autorização para realização da pesquisa, dirigido ao responsável pela Diretoria Regional de Ensino.

- Carta de solicitação de autorização dos pais para a participação de seus filhos no processo de realização do estudo, conforme estabelecido no Decreto ${ }^{\circ}$ 93.933, de 14 de janeiro de 1998, do Conselho Nacional de Saúde, que trata dos procedimentos de pesquisa envolvendo seres humanos.

- Roteiro Norteador, constituído de 15 perguntas abertas, tendo por objetivo identificar as idéias, as crenças e os conceitos da professora, em questões referentes ao processo de ensino e de aprendizagem do aluno com deficiência.

- Filmadora, vídeo-cassete e gravador.

\section{Coleta de dados}

Tendo sido obtida a aprovação dos pais, da Diretoria Regional de Ensino e da Diretoria da Unidade, iniciou-se a filmagem, em VT, da prática de ensino da professora, no cotidiano da sala de aula, no período compreendido entre os meses de março a novembro. A filmagem foi realizada três vezes por semana, tendo a duração de 10 minutos cada uma. Os horários para a filmagem foram acidentais ${ }^{2}$, objetivando tanto a apreensão de atividades diversificadas, já que a professora costumava adotar, a cada dia, a mesma seqüência de abordagem dos diferentes componentes curriculares, como também diminuir a possibilidade da professora se "preparar" para o registro.

\section{Escolha das cenas a serem analisadas}

Ao término de cada semana de filmagem, a pesquisadora assistia aos filmes e escolhia, dentre os vários VT's, o que melhor mostrava a interação da professora com seus alunos, em sua prática pedagógica. A escolha obedeceu aos seguintes critérios:

- Conteúdo do filme - foram selecionados os filmes nos quais a professora aparecia em interação com os alunos, desprezando-se aqueles nos quais ela permanecia, por exemplo, escrevendo na lousa, ou não se encontrava na sala.

- Estratégia pedagógica - foram selecionados filmes nos quais se encontrava registrado o uso de diferentes estratégias pedagógicas para o ensino dos conteúdos.

- Grau de dificuldade - deu-se preferência aos filmes nos quais a professora e/ou os alunos demonstravam dificuldades e/ou dúvidas acerca da realização da atividade proposta. 


\section{Encontros para interação reflexiva}

A cada semana realizava-se um encontro entre pesquisadora e professora para reflexão e análise sobre a prática pedagógica da professora, durante seu processo de ensino. Foram realizados 20 encontros $^{3} \operatorname{com}_{\text {duração média de } 90}$ minutos. A cada encontro, focalizava-se o filme selecionado na semana anterior. Este era assistido em conjunto, pela pesquisadora e pela professora, as quais analisavam o que estava acontecendo nas diferentes cenas. A partir do segundo encontro, decidiu-se pela introdução da leitura prévia de textos teóricos, como preparação para o momento de reflexão, em função de dúvidas da professora com relação ao processo de aprendizagem e à relação de seu ensino com esse processo. A escolha dos textos foi determinada pelas necessidades apresentadas pela professora a cada encontro, surgidas durante a discussão sobre suas dificuldades no trato pedagógico com seus alunos. Assim, os encontros subseqüentes foram iniciados com a discussão sobre o texto disponibilizado pela pesquisadora e lido previamente pela professora, passando-se, então, à discussão sobre as cenas contidas no filme.

\section{Análise das cenas à luz do roteiro norteador}

A análise, de maneira geral, fundamentou-se na discussão sobre o que estava acontecendo em cada conjunto de cenas: o que a professora estava fazendo, por que o estava fazendo, o que o aluno estava fazendo, por que o estava fazendo, que dificuldades o aluno estava enfrentando, que necessidades educacionais ele apresentava e o que a professora poderia fazer para responder às necessidades dele e promover a superação de tais dificuldades. Para tanto, recorreu-se à aplicação de um Roteiro Norteador, já utilizado em estudos anteriores, nos quais se mostrou um instrumento eficaz para a promoção da compreensão sobre o fenômeno registrado (Almeida, 1994; Aranha, 1998; Leite, 1997).

As questões do Roteiro Norteador foram utilizadas como estímulos iniciais para a reflexão, tendo-se permitido a liberdade de encaminhar a discussão para idéias, dúvidas e considerações que surgiam no decorrer da interação, mesmo quando estas não se encontravam diretamente relacionadas com a questão inicial. Este método de reflexão permitiu o desvelamento de crenças e concepções da professora, a caracterização e a compreensão de sua prática pedagógica à luz de conteúdo teórico-metodológico, além de favorecer o repensar dessa prática. O conteúdo das interações ocorridas nos 20 encontros foi gravado, para posterior análise.

\section{Procedimento de análise}

Primeiramente, foi transcrito, na íntegra, o conteúdo gravado nos 20 encontros. As transcrições foram lidas, seqüencialmente, inúmeras vezes. Na leitura seqüencial, constatou-se a presença de mudanças nas concepções e idéias da professora acerca dos processos de ensino, de aprendizagem e de sua prática de administração do ensino na diversidade. Buscou-se, então, desenvolver um sistema de análise que garantisse a apreensão e a descrição sistemática, clara e objetiva dessas mudanças.Após várias tentativas de construção de um sistema que atendesse a esse objetivo, encontrou-se o caminho finalmente adotado.

Definiu-se, inicialmente, como critério para a análise, um conjunto de indicadores elaborado por especialistas atuantes na área de Educação em diferentes instituições de ensino superior no país (UFSCar, UNIMEP, Unesp-Marília, Unesp-Bauru, UERJ, Unicamp, UFMS e USP). Para tanto, foram enviadas mensagens, por correio eletrônico, a 22 especialistas em Educação Especial, solicitando que listassem cinco indicadores que consideravam indispensáveis a um professor de classe especial para a efetivação de um ensino competente e eficiente. Desses, 13 especialistas responderam à solicitação, enviando os indicadores que entendiam atender a essa característica.

Os indicadores propostos foram: a) ser flexível (53,8\%); b) ter embasamento teórico $(53,8 \%)$; c) ter domínio didático $(38,4 \%)$; d) ter interesse em formação contínua $(30,7 \%)$; e) apresentar flexibilidade ao avaliar $(23 \%)$; f) ter ética profissional $(23 \%)$; g) ter competência política $(23 \%)$; h) ser criativo (23\%); i) ter compreensão de deficiência $(15,4 \%)$; j) trabalhar com interdisciplinaridade $(15,4 \%) ; 1)$ ser reflexivo $(15,4 \%) ; \mathrm{m})$ ensinar pesquisando $(15,4 \%) ; \mathrm{n})$ ser mediador do conhecimento $(7,6 \%)$; o) dominar conteúdo $(7,6 \%) ; \mathrm{p})$ ser favorável à inclusão (7,6\%).

Os indicadores acima propostos foram, então, analisados à luz do conteúdo encontrado na literatura (Almeida, 1994; Aranha, 1998; Basso, 1998; Kassar, 1999; Libâneo, 2001; Nogueira, 1993; Oliveira, 2002; Padilha, 1997, 2001; Pinto, 1999; Sanches, 1995; Smolka, 2000; Zanotto, 2002) e dos dados coletados. A partir dessa análise, foram feitos ajustes no sistema de categorias, de forma que este contemplasse tanto os indicadores apontados pelos especialistas e pela literatura, bem como as manifestações verbais da professora.

Em função do número elevado de dados, o sistema de categorias foi subdividido em três áreas de investigação ${ }^{4}: 1$ ) formação docente; 2) prática pedagógica em sala de aula; 3 ) relatos da professora.

Considerando-se a necessidade de se estabelecer os critérios a serem utilizados pelo observador para delimitar o início e o fim de uma sequiência comportamental, quando se quer quantificar os comportamentos (Danna \& Matos, 1984), definiu-se como unidade de análise "o conjunto de falas da professora, antecedidas ou não de falas da pesquisadora, versando sobre um determinado assunto" (p. 151). A pesquisadora, então, dividiu o conteúdo dos encontros em unidades de análise tendo como parâmetro a definição adotada. Para garantir a fidedignidade da divisão das falas em unidades, amostras da transcrição foram encaminhadas para três consultores, com experiência em pesquisa científica, para que estes também as delimitassem, independentemente. Foi, então, calculado o índice de concordância entre a delimitação em unidades feita pelos consultores e aquela feita pela pesquisadora. O primeiro consultor $(\mathrm{C} 1)$ recebeu 14 páginas de transcrição, escolhidas através de sorteio, correspondendo a $10 \%$ do total de páginas transcritas. O índice de concordância obtido foi de $83,08 \%$. Outros dois consultores receberam a

4 A definição das categorias e suas respectivas subcategorias encontra-se na tese, que está disponível em: http://www.biblioteca.unesp.br/bibliotecadigital/document/?did=1547 
transcrição integral de um encontro ( $2^{\circ}$ encontro), também escolhido através de sorteio. O material a eles encaminhado consistiu de 22 páginas transcritas. $\mathrm{O}$ índice de concordância obtido foi de $86,2 \%$ com C2, e de $92,8 \%$ com C3.

Em seguida, a pesquisadora fez uma primeira classificação das unidades de análise do $2^{\circ}$ encontro, a partir das categorias constantes do sistema de análise. As falas da pesquisadora, embora consideradas no processo de divisão das transcrições em unidades de análise, não foram tratadas na classificação, dados os objetivos deste estudo. Para verificar se as definições constantes do sistema estavam claras e objetivas e se as categorias eram mutuamente excludentes, encaminhou-se a transcrição deste encontro para outros dois consultores, solicitando-se destes que fizessem a classificação das unidades. O índice de concordância obtido foi de $92,1 \%$ com C4 e de $89,5 \%$ com C5.

Tais procedimentos foram adotados porque, segundo Martins (2000), na pesquisa qualitativa, o ato de descrever algo a alguém é uma tarefa difícil, que implica apresentar à pessoa que não o conhece, algo com determinada função. Para que a descrição atinja seu objetivo, é necessário garantir-se sua precisão, através da certificação da clareza e objetividade das definiçõos utilizadas.

Tendo asseguradas a confiabilidade da divisão do material transcrito em unidades e a adequação do sistema de categorias, passou-se, então, à classificação definitiva das unidades de análise registradas nas sessões escolhidas para a análise: encontros 2, 3, 10, 11, 18 e 19, correspondentes a $30 \%$ do total de encontros realizados. Estes encontros foram escolhidos por representarem o início, o meio e o final do processo de reflexão sobre a prática pedagógica da professora. Foram desconsiderados o primeiro, por ser o encontro para rapport e também porque o Roteiro Norteador foi modificado após sua realização, e o último, por não ter sido utilizado para discutir sobre a prática da professora, mas sim, para analisar o processo de reflexão realizado durante o ano.

Os dados obtidos foram tratados quantitativamente, calculando-se freqüência absoluta e relativa de cada categoria. Em seguida, desenvolveu-se análise qualitativa, buscando identificar o significado dessa frequiência, à luz do conteúdo das falas.

\section{Resultados}

Os resultados serão apresentados em duas áreas de investigação, que compreendem temáticas distintas: formação docente e prática pedagógica.

Conforme se pode verificar na Tabela 1, o tema formação docente foi abordado, pela professora, 49 vezes. $\mathrm{O}$ maior número de falas se referiu à categoria "compreensão da prática educacional" (16 ocorrências), na subcategoria "natureza focal" (94\%), em que a professora descreveu a sua prática de ensino como um fenômeno isolado, restrito a um determinado momento e situação. Isto sinaliza uma compreensão reducionista, já que ignora os múltiplos determinantes presentes em cada situação de ensino. É interessante apontar que a freqüência dessa subcategoria se reduziu, do início para o final do processo de reflexão (do $2^{\circ}$ ao $19^{\circ}$ encontro), e que no último, a professora analisou sua prática de ensino, sob um enfoque sócio-político (6\%). Isso pode ser indicativo de que à medida que se avançou no processo de reflexão teórico-metodológica, a atenção da professora se deslocou, da relação linear ação do professor - ação do aluno, para a consideração de outros aspectos constituintes da relação de ensino e de aprendizagem.

A categoria "valorização da formação continuada" ocorreu 14 vezes, sendo que em $100 \%$ das vezes a professora manifestou considerá-la favoravelmente. Esse fato é indicativo de que a professora considera importante o processo de formação continuada, para melhoria de sua prática pedagógica. A análise qualitativa do conteúdo das falas mostrou que a maneira como foi apresentada a proposta de formação continuada, adotada neste estudo, despertou o interesse da professora, por ter a oportunidade de externar suas dúvidas, questionamentos e opiniões. Esses dados confirmam os resultados constantes de relatos de pesquisa realizadas nesta área, os quais apontam, dentre outros fatores, que programas de educação continuada têm sido bem aceitos quando propostos em condições de parceria (Almeida, 1994; André, 1995; Dechichi, 2001; Del Prette \& cols., 1998; Zanotto, 2002). Com efeito, a formação continuada deve ser um processo reflexivo que possa, entre outros aspectos,

Tabela 1. Freqüência das categorias das falas da professora relativas à formação docente

\begin{tabular}{|c|c|c|c|c|c|c|c|c|c|c|c|}
\hline \multirow[t]{2}{*}{ Categorias } & \multirow[t]{2}{*}{ Subcategorias } & \multirow[t]{2}{*}{2} & \multirow[t]{2}{*}{3} & \multirow[t]{2}{*}{10} & \multirow[t]{2}{*}{11} & \multirow[t]{2}{*}{18} & \multirow[t]{2}{*}{19} & \multicolumn{2}{|c|}{$\begin{array}{c}\begin{array}{c}\text { Freqüência } \\
\text { subcategoria }\end{array} \\
\end{array}$} & \multicolumn{2}{|c|}{$\begin{array}{c}\text { Freqüência } \\
\text { Categoria }\end{array}$} \\
\hline & & & & & & & & Absoluta & Relativa & Absoluta & Relativa \\
\hline \multirow[t]{2}{*}{ Valorização ed.continuada } & Favorável & 3 & 3 & 2 & 2 & 2 & 2 & 14 & 100 & 14 & 28,6 \\
\hline & Desfavorável & 0 & 0 & 0 & 0 & 0 & 0 & 0 & 0 & & \\
\hline \multirow[t]{2}{*}{ Embasamento teórico } & Valorização & 0 & 0 & 0 & 0 & 2 & 0 & 2 & 25 & 8 & 16,3 \\
\hline & Desvalorização & 1 & 2 & 1 & 0 & 1 & 1 & 6 & 75 & & \\
\hline \multirow[t]{2}{*}{ Compreensão prática educacional } & Sócio-política & 0 & 0 & 0 & 0 & 0 & 1 & 1 & 6 & 16 & 32,6 \\
\hline & Focal & 5 & 4 & 1 & 2 & 2 & 1 & 15 & 94 & & \\
\hline \multirow[t]{2}{*}{ Concepção de aluno } & Passivo & 0 & 5 & 1 & 0 & 0 & 0 & 6 & 60 & 10 & 20,4 \\
\hline & Ativo & 0 & 0 & 1 & 0 & 2 & 1 & 4 & 40 & & \\
\hline \multirow[t]{2}{*}{ Compreensão da deficiência } & Multi-determinada & 0 & 0 & 0 & 0 & 0 & 0 & 0 & 0 & 1 & 2,0 \\
\hline & Focal & 0 & 0 & 1 & 0 & 0 & 0 & 1 & 100 & & \\
\hline Total & & 9 & 14 & 7 & 4 & 9 & 6 & & & 49 & 100 \\
\hline
\end{tabular}


propiciar atualizações, aprofundamento das temáticas educacionais e apoiar-se numa reflexão sobre a prática educativa, promovendo um processo constante de auto-avaliação que oriente a construção contínua de competências profissionais". Ainda, "um processo de reflexão exige predisposição a um questionamento crítico da intervenção educativa e uma análise da prática na perspectiva de seus pressuposta. (Referenciais para a formação dos professores, 1999, p. 70)

A categoria "concepção de aluno" ocorreu 10 vezes durante os encontros. Em 60\% dessas vezes, a professora referiu-se ao aluno como sendo um receptáculo "passivo" (seis ocorrências) e 40\%, como agente "ativo" no processo de ensino e de aprendizagem (quatro ocorrências). Pode-se constatar que a professora apresentou mudança em sua concepção de aluno, de passivo a ativo, no decorrer da seqüência de encontros, já que a subcategoria "passivo" ocorreu no início (cinco vezes) e no meio (uma vez) do processo, não mais ocorrendo até o final, enquanto que a subcategoria "ativo" ocorreu uma vez no período intermediário e três vezes nos últimos encontros.

A categoria "embasamento teórico" ocorreu oito vezes, sendo que seis delas se referiram a relatos constantes da subcategoria "desvalorização do embasamento teórico" e duas delas, à subcategoria "valorização do embasamento teórico". Isso indica quão pouca importância a professora atribui a um sistema teórico que dê sentido e significado a sua prática pedagógica. Constatou-se, inclusive, que mesmo após a inserção de estudo e debate sobre textos teóricos no processo de intervenção reflexiva, a professora não apoiou sua análise nos pressupostos discutidos.

A categoria "compreensão de deficiência" ocorreu somente uma vez, no $10^{\circ}$ encontro. Isso pode ter ocorrido porque durante as reflexões não foram discutidas questões que solicitassem da professora manifestação sobre sua compreensão específica acerca da deficiência. Na única vez em que esse assunto foi abordado, a professora apresentou uma compreensão "focal", descrevendo a deficiência como um fenômeno de natureza exclusivamente biológica.
Conforme se pode constatar na Tabela 2, a maioria das falas da professora referiu-se à atribuição de causalidade aos problemas encontrados no processo de ensino e de aprendizagem. Em 53\% das ocorrências, os problemas foram atribuídos à escassez ou inadequação de recursos didático-pedagógicos; $36 \%$ deles foram atribuídos ao aluno, responsabilizado pela sua não aprendizagem; $11 \%$ foram atribuídos a limitações da professora. É interessante apontar que a atribuição de causalidade dos problemas voltou-se para o aluno, durante todo o processo; já que a atribuição pela falta de recursos teve maior incidência no início do processo, tendo diminuído gradativamente até o final. A responsabilização do professor, ausente no início do processo de reflexão crítica sobre a prática pedagógica, começou a ocorrer nos encontros intermediários, aumentando gradativamente à medida que eles se desenvolveram. Isso não significa que o processo veio remeter a culpa à professora, mas sim, que esta passou a identificar, com mais clareza, os diferentes determinantes do insucesso no cotidiano pedagógico.

Grande parte das falas da professora, $29 \%$, foi classificada na categoria "Propostas Educacionais" (31 ocorrências). Em $71 \%$ destas (22), a professora desvelou um ensinar pesquisando, enquanto que em $19 \%$ (seis) delas, mostrou um ensino autoritário. É interessante apontar que no decorrer das três etapas do processo reflexivo, o foco perceptual da professora mudou, já que no início ela relatou ensinar pesquisando somente uma vez em cada encontro, enquanto que a partir do $10^{\circ}$ encontro a ocorrência aumentou, chegando a acontecer oito vezes no $18^{\circ}$ encontro. Em contrapartida, o ensino autoritário, conceituado como a suposição da transmissão mecânica de conhecimentos da professora para o aluno, ocorreu cinco vezes, nos encontros 2 e 3 , voltando a ocorrer uma única vez no $11^{\circ}$ encontro.

A categoria "Prática Pedagógica" apresentou uma freqüência de 20 ocorrências, perfazendo 18,7\% das falas da professora. Dentre essas, em 60\% (12 ocorrências) a professora relatou, ao analisar sua prática pedagógica, promover ajustes em sua prática de ensino, seja nos objetivos educacionais, nos conteúdos, nos recursos pedagógicos utilizados e nos proce-

Tabela 2. Frequiência das categorias das falas da professora referentes à prática pedagógica

\begin{tabular}{|c|c|c|c|c|c|c|c|c|c|c|c|}
\hline \multirow[t]{2}{*}{ Categorias } & \multirow[t]{2}{*}{ Subcategorias } & \multirow[t]{2}{*}{2} & \multirow[t]{2}{*}{3} & \multirow[t]{2}{*}{10} & \multirow[t]{2}{*}{11} & \multirow[t]{2}{*}{18} & \multirow[t]{2}{*}{19} & \multicolumn{2}{|c|}{$\begin{array}{c}\text { Freqüência } \\
\text { subcategoria }\end{array}$} & \multicolumn{2}{|c|}{$\begin{array}{c}\text { Freqüência } \\
\text { categoria }\end{array}$} \\
\hline & & & & & & & & Absoluta & Relativa & Absoluta & Relativa \\
\hline Domínio didático-pedagógico & & 0 & 1 & 2 & 0 & 2 & 2 & - & - & 7 & 6,5 \\
\hline \multirow{4}{*}{ Propostas educacionais } & Ensinar pesquisando & 1 & 1 & 4 & 5 & 8 & 3 & 22 & 71 & \multirow{4}{*}{31} & \multirow{4}{*}{29} \\
\hline & Ensinar transversa/e & 0 & 0 & 1 & 1 & 0 & 0 & 2 & 6 & & \\
\hline & Ensinar focalmente & 0 & 0 & 0 & 0 & 0 & 1 & 1 & 3 & & \\
\hline & Ensinar autoritariamente & 3 & 2 & 0 & 1 & 0 & 0 & 6 & 19 & & \\
\hline \multirow{2}{*}{ Prática pedagógica } & Flexível & 1 & 1 & 3 & 0 & 4 & 3 & 12 & 60 & \multirow{2}{*}{20} & \multirow{2}{*}{18,7} \\
\hline & Rígida & 4 & 3 & 0 & 1 & 0 & 0 & 8 & 40 & & \\
\hline \multirow{3}{*}{$\begin{array}{l}\text { Atribuição causalidade aos problemas } \\
\text { do processo ensino-aprendizagem }\end{array}$} & Ao professor & 0 & 0 & 0 & 1 & 0 & 3 & 4 & 11 & \multirow{3}{*}{36} & \multirow{3}{*}{33,7} \\
\hline & Ao aluno & 1 & 7 & 1 & 1 & 2 & 1 & 13 & 36 & & \\
\hline & Ao recurso & 7 & 6 & 3 & 2 & 0 & 1 & 19 & 53 & & \\
\hline \multirow{2}{*}{ Comportamento do aluno } & Uniforme & 0 & 0 & 0 & 0 & 0 & 0 & 0 & 0 & \multirow{2}{*}{13} & \multirow{2}{*}{12,1} \\
\hline & Diversificado & 0 & 2 & 0 & 0 & 6 & 5 & 13 & 100 & & \\
\hline Total & & & & & & & & & & 107 & 100 \\
\hline
\end{tabular}


dimentos de avaliação. Em $40 \%$ (oito) a professora relatou ensinar a todos os alunos de uma mesma maneira, a partir da adoção de um plano de ensino único, não mencionando a promoção de ajustes em sua prática pedagógica. Apesar da categoria ter obtido uma freqüência baixa, é interessante apontar que, no decorrer do ano, a prática flexível aumentou de frequiência, enquanto que a prática rígida diminuiu gradativamente, não ocorrendo nos dois últimos encontros. Isso pode indicar uma tendência de mudança em sua postura pedagógica, no decorrer do tempo de reflexão crítica.

A categoria "Comportamento do aluno" ocorreu em $12,1 \%$ das falas da professora (13 ocorrências), já que em $100 \%$ das vezes ela descreve que os alunos se comportam de modo diferenciado, diante de uma dada atividade, identificando-os como participativos nas propostas apresentadas no ambiente educacional. Há que se ressaltar, ainda, que a freqüência aumentou no decorrer dos encontros.

A categoria "domínio didático-pedagógico" foi a que apresentou menor ocorrência nas falas da professora durante o conjunto de encontros (sete ocorrências), perfazendo um percentual de $6,5 \%$. Nessas ocasiões, pôde-se apreender que a professora demonstrou domínio do conteúdo ministrado por ela nos diferentes componentes curriculares.

\section{Discussão}

A partir da análise dos resultados apresentados nas Tabelas 1 e 2 percebe-se que a professora apresentou algumas mudanças ao relatar sobre temáticas relacionadas a sua prática pedagógica, que serão destacadas abaixo. Isso pode ser verificado na análise de seu relato verbal, expressado nos encontros realizados durante o período de reflexão interativa.

Primeiramente, pôde se perceber que a professora começa a considerar, nos seus relatos, a promoção de atividades que estimulem a participação dos alunos. Passa a propiciar, desse modo, situações pedagógicas motivadoras, que acabam por gerar momentos de aprendizagem em que o aluno deixa de ser um mero espectador, ou ainda, simplesmente tarefeiro. Isso é importante, pois, o modo como o professor entende o seu alunado, em grande parte, é indicativo de como norteia a sua prática em sala de aula, uma vez que as ações pedagógicas acabam por desvelar a adoção de práticas imbuídas de seus preconceitos em relação ao desempenho dos alunos. Isso se torna mais comum na educação especial, quando se pressupõe, ou julga-se, de modo errôneo, a capacidade de realização de determinada tarefa por parte dos alunos (Kassar, 1999; Padilha, 1997).

Ainda, segundo Oliveira (1995), a escola deve ser o local em que o processo de ensino e aprendizagem ocorre de forma intencional, através de intervenções que veiculem a transmissão de conhecimentos e o favorecimento da apropriação dos saberes. Desse modo, "o professor é uma pessoa real, fisicamente presente diante daquele que aprende, com o papel de interferir no processo de aprendizagem (e, portanto no desenvolvimento) provocando avanços que não ocorreriam espontaneamente" (p. 58). Para que isso se concretize, é necessário que o professor perceba o aluno como um personagem que participa do processo educacional, observando as suas reações comportamentais e seu desempenho, diante da realização das atividades propostas.
Em relação à atribuição das causas dos problemas no processo de ensino e aprendizagem, nota-se, porém, uma tendência de mudança nas falas da professora, quando a incidência da subcategoria "aluno" e "recurso" diminuem e surge a subcategoria "professor". Isso pode ser indicativo de que a professora começa a se responsabilizar também pelo fracasso educacional, refletindo sobre os problemas de ensino e aprendizagem, em sala de aula, como possíveis falhas da sua atuação pedagógica.

Na tentativa de se estabelecer o processo de ensino e aprendizagem, o professor acaba por se deparar com questões que exigem reflexão sobre a sua forma de atuar, pois, freqüentemente, acaba por responsabilizar o aluno ou a falta de recursos pedagógicos pelo fracasso educacional. Esse dado parece ser comum na Educação Especial, por dois motivos.

Primeiro, por conta da especificidade de seu alunado, que traz embutida no rótulo de deficiente a condição de incapaz ou com grande dificuldade em aprender. Essa condição parece ser crucial para se atribuir somente ao aluno a não aprendizagem dos conteúdos ministrados em sala de aula, através da adoção do legado da impossibilidade - ou possibilidade restrita - de aprendizagem do deficiente mental.

Um outro fator sobre a responsabilidade do ensino referese à falta de recursos pedagógicos, uma vez que esses são entendidos erroneamente como responsáveis pelo processo de aquisição de conhecimentos dos aprendizes, sobrepondo-se, inclusive, aos objetivos e conteúdos educacionais. A dificuldade econômica enfrentada por grande parte das classes especiais, na rede pública de ensino, produz, no professor, uma falsa sensação de ineficiência, uma vez que os recursos pedagógicos preferidos não fazem parte da sua realidade, mas se encontram aquém de suas possibilidades reais de utilização.

Glat (1999), ao realizar uma pesquisa com professores da Educação Especial, relata que a falta de recursos materiais é algo muito frequiente nas queixas de tais professores, quando descrevem o cotidiano escolar. Não obstante, considera que " $a$ falta de recursos materiais, embora limite às ações pedagógicas, não é impeditiva de um trabalho de qualidade" (p. 59).

Ao pensar dessa maneira, o professor incorre em outro erro, pois, além de não valorizar os materiais que possui no seu próprio ambiente de aprendizagem, atribui ao recurso uma função de relevância maior, ou seja, a atividade elaborada pelo professor acaba sendo determinada pela possibilidade do emprego de um dado recurso e não pelos objetivos educacionais propostos em planejamento.

Já a análise dos relatos sobre a prática pedagógica indica que a professora desenvolveu tentativas de criar situações educacionais que fossem responsivas às necessidades de seus alunos. Essa atuação vem ao encontro do que é apontado por vários estudos na Educação Especial, que priorizam, entre outros aspectos, que o professor deve atender às peculiaridades de seu alunado e que, para que isso ocorra, faz-se necessário apresentar flexibilidade na sua atuação, promovendo ajustes em algum ou em vários aspectos do seu planejamento de ensino (Bueno, 1993; Glat, 1999; Mazzotta, 1996).

Fazendo um cotejo dos dados obtidos na categoria "prática pedagógica flexível" com os da categoria "rigidez pedagógica", percebe-se um dado interessante durante o desenvolvimento da proposta de intervenção, pois se nota 
que a primeira aumenta a sua ocorrência e, em contraposição, a segunda diminui gradativamente, não ocorrendo nos dois últimos encontros. Tais aspectos revelam que a professora apresenta uma tendência de mudança, ao mencionar sobre sua postura pedagógica. Portanto, a proposta de formação continuada parece ter provocado na professora um repensar da sua prática pedagógica, adotando situações em sala de aula que promovam ajustes pedagógicos em prol do seu aluno, fato notado em suas falas.

Desse modo, concorda-se com Altet (2001), quando a autora enfatiza que é função do professor promover ajustes pedagógicos nas suas ações, pois

a Pedagogia concorre para a transformação da informação em Saber através de trocas cognitivas e sócio-afetivas trazidas pelo professor por meio de interações, retroações, ajustes, adaptações interpessoais e aplicações em sala de aula, durante o tempo real em que ocorre a intervenção. (p. 27)

Uma outra tendência de mudança na análise dos relatos da professora sobre a sua prática refere-se às propostas de educação adotadas. Isso pode ser constatado quando se observa que há um aumento de relatos que indicam um modo de ensinar pesquisando em detrimento de um ensino autoritário. Tais fatos levam a entender que a professora deixa de relatar ações pedagógicas que reproduzem o modelo de ensino autoritário, unilateral, em que não se veicula o saber compartilhado.

Segundo Laranjeira (2000), o professor, no trato pedagógico, acaba por confundir autoridade no ensino com autoritarismo. A autora salienta que o professor, ao adotar um modelo autoritário, muitas vezes pensa que está efetivando uma relação de ensino e aprendizagem baseada na imposição, na qual os alunos acolhem tudo o que ele manda sem maiores questionamentos, desvelando, por fim, uma prática reprodutora de conhecimentos. Na verdade, a adoção dessa prática parece esconder uma postura que deixa de garantir a efetivação do processo de ensino e aprendizagem, já que não permite aos alunos a possibilidade de um espaço educacional em que possam participar ativamente, colocando suas inquietações e contribuindo com suas próprias colocações.

A análise dos dados referentes à "valorização da educação continuada" desvela alguns fatos interessantes. Primeiro, a maneira como foi apresentada a proposta de formação continuada parece ter provocado interesse por parte da professora, pois participava do debate externando suas dúvidas, questionamentos e opiniões. Isso também pode ser percebido pela sua anuência aos encontros e pela disponibilidade em receber as críticas realizadas.

Também a idéia de se adotar um programa de intervenção que oferecesse suporte educacional às posturas adotadas em sala de aula, porém que respeitasse as suas concepções e estratégias pedagógicas, talvez tenha contribuído para a ocorrência de relatos da professora que indicassem a valorização da educação continuada.

Em contrapartida, a fundamentação teórica acabou não sendo um tema contemplado durante a intervenção reflexiva, pois a professora deixa de relatar atitudes pedagógicas, em ambiente de ensino, que estivessem embasadas em alguma abordagem teórica. Dessa maneira, suas falas acabam por contradizer o princípio de que a prática educacional deve estar fundamentada em algum edifício teórico, que, por sua vez, oriente a elaboração de um projeto pedagógico e permita a utilização de ações pedagógicas diferenciadas, as quais possam atender às necessidades educacionais dos alunos.

Um outro dado que chama a atenção se refere ao fato de que, mesmo com a inserção do debate de questões teóricas, durante a intervenção reflexiva, a professora deixa de realizar a análise de seus comportamentos à luz de pressupostos teóricos, não indo ao encontro da expectativa da pesquisadora.

Entretanto, observou-se, assistematicamente, que essa prática adotada, além de servir como suporte teórico para o esclarecimento dos questionamentos apresentados pela professora, acabou por favorecer uma possibilidade de aprofundamento teórico, garantindo o contato com referências bibliográficas relacionadas às questões debatidas.

Percebe-se também que a professora relatou compreender a sua prática de modo focalizado, deixando de apresentar as considerações sociopolíticas que a envolvem. O fato de a professora apresentar esse olhar focal sobre seu ensino sinaliza uma atitude reducionista, em sua prática pedagógica, já que parece não vinculá-la aos múltiplos determinantes que se encontram presentes, em cada situação de ensino.

A circunstância de também abordar o conteúdo dessa categoria cada vez menos, à medida que se avança no processo de reflexão interativa, pode talvez se atribuir ao deslocamento de sua atenção, das suas ações em si, para outros aspectos, teóricos ou não, discutidos durante os encontros reflexivos.

Segundo Mazzilli e Muramoto (1998), o educador, durante a sua formação, muitas vezes, não entra em contato com reflexões que lhe permitam elaborar um projeto educacional que esteja vinculado diretamente a um projeto sócio-político. Com isso, o professor acaba por se desvincular, em sua prática, de aspectos relacionados a contextos sociais e a concepções políticas.

Por último, a intervenção reflexiva realizada infelizmente deixou de possibilitar a manifestação da professora sobre como compreende a deficiência, porém a única vez em que isso ocorre revela que ela a analisa enquanto um fenômeno exclusivamente de origem biológica. Isso vem demonstrar que esse determinante, muitas vezes, acaba por permear a concepção de deficiência apresentada pelo professor da Educação Especial, julgando o aluno como limitado e incapaz, a partir das suas diferenças sensoriais, cognitivas ou motoras. Padilha (2001) ressalta que fica difícil estabelecer uma proposta educacional adequada, enquanto entendermos a deficiência como fenômeno apenas biológico, em que se pressupõe que o deficiente é menos do que alguém ou que lhe falta algo.

A escola, por preconceito ou desinformação, também discrimina, muitas vezes, o aluno com deficiência, quando seus professores lhe delegam apenas uma determinada parcela de aprendizagens, sob a alegação de serem incapazes de aprender. Ao adotar essa prática, acaba por restringir o acesso do deficiente a grande parte do saberes historicamente construídos. Vygotsky, Luria e Leontiev (1988) oferecem outra contribuição quando destacam as interações e relações sociais como contexto da construção de conhecimento, fundamental para o desenvolvimento das funções psicológicas superiores. 


\section{Considerações Finais}

A adoção do Roteiro Norteador, durante os encontros entre pesquisadora e professora, foi tida como uma estratégia metodológica facilitadora para analisar as situações educacionais filmadas, pois suas questões permitiram analisar a dinâmica do processo de ensino e aprendizagem de forma reflexivo-crítica, desvelando as crenças e concepções da professora e podendo, conseqüentemente, caracterizar a sua prática pedagógica, além de favorecer o estabelecimento de um "espaço" interacional que possibilitasse o repensar da prática educacional.

Em síntese, talvez o fato de a professora refletir sobre tais posicionamentos, isto é, olhar para a sua prática e analisá-la com um interlocutor-observador externo, parece ter provocado o repensar da sua própria atuação e participação no processo educacional, podendo, agora, perceber-se como responsável pela aprendizagem e, sobretudo, pela dificuldade de aprendizagem identificada no comportamento de seus alunos, ao desempenharem as atividades propostas.

Assim, entende-se, mais uma vez, que a oportunidade do enfrentamento da análise de suas próprias ações garantiu, entre outras coisas, o entendimento da complexidade do processo educativo, levando-a a perceber que não existe uma causa isolada para seu fracasso ou sucesso e, sim, um conjunto de fatores que podem ocasioná-lo, cabendo ao professor a condução para que se dê a sua plena efetivação.

A fundamentação teórica adotada para embasar as discussões realizadas contribuiu, e muito, para a execução da pesquisa, uma vez que a leitura da Psicologia sócio-histórica pode facilitar, entre outros aspectos, a compreensão da escola enquanto um local de práticas educacionais transformadoras da realidade social e do papel do professor enquanto mediador do conhecimento. Sua adoção também demonstrou que a reflexão conjunta possibilita novas condições de aprendizagem, as quais favorecem a apropriação de significados teóricos, percebidos tanto na relação pesquisadora-professora, quanto na professora-aluno.

A educação continuada parece ser somente possível quando se consegue criar uma situação que seja capaz de estabelecer um vínculo cooperativo entre professor e pesquisador. Situações em que um possa realmente auxiliar o outro, sem prepotência de nenhuma das partes, pois o pesquisador, ao assumir a postura de observador externo ao cotidiano educacional, deve estar ciente de que a responsabilidade do ensino é do professor e cabe ao pesquisador auxiliá-lo nessa tarefa, apontando novas possibilidades para entendê-la ou efetivá-la, no cotidiano escolar.

\section{Referências}

Almeida, N. V. F. (1994). Os modos de pensar do professor: Buscando compreendê-los a partir de contextos interativos. Tese de Doutorado, Universidade Estadual de Campinas, Campinas.

Altet, M. (2001). As competências do professor profissional: Entre conhecimentos, esquemas de ação e adaptação, saber analisar. Em P. Perrenoud, L. Paquay, M. Altet \& E. Charlier (Orgs.), Formando professores profissionais: Quais estratégias? Quais competências? (p. 23-32). Porto Alegre: Artmed.
André, M. I. do N. (1995). Como os professores de educação especial concebem suas ações em sala de aula: Um estudo comparativo entre novatos e experientes. Dissertação de Mestrado, Universidade Federal de São Carlos, São Carlos.

Aranha, M. S. F. (1998). Mudando o pensar do instrutor, através de reflexão teórico-metodológica sobre sua prática cotidiana de ensino. Manuscrito não publicado.

Basso, I. S. (1998). Significado e sentido do trabalho docente. Cadernos CEDES, 19(44), 19-30.

Brasil (1999). Referenciais para a formação de professores. Secretaria de Educação Fundamental. Brasília: Secretaria de Educação Fundamental.

Bueno, J. G. S. (1993). Educação especial brasileira: Integração/ segregação do aluno diferente. São Paulo: EDUC.

Candau, V. M. F. (1996). Formação continuada de professores: Tendências atuais. Em A. M. M. R. Reali \& M. G. N. Mizukami (Orgs.), Formação de professores: Tendências atuais (pp. 139152). São Carlos: EDUFSCar.

Conselho Nacional da Saúde (1998). Resolução n. 196/96 sobre a pesquisa envolvendo seres humanos. Bioética, 7(2). Brasília: Conselho Nacional de Saúde.

Correa, L. M. (1999). Alunos com necessidades educativas especiais nas classes regulares. Porto: Porto Editora.

Danna, M. F. E \& Matos, M. A. (1984). Ensinando observação: Uma introdução. São Paulo: EDICON.

Dechichi, C. (2001). Transformando o ambiente de sala de aula em um contexto promotor do desenvolvimento do aluno deficiente mental. Tese de Doutorado, Pontifícia Universidade Católica de São Paulo, São Paulo.

Del Prette, Z. A. P., Del Prette, A., Garcia, F. A., Silva, A. T. B. \& Puntel, L. P. (1998). Habilidades sociais do professor em sala de aula: um estudo de caso. Psicologia Reflexão e Crítica, 11(3), 611-623.

Fusari, J. C. \& Rios, T. A. (1994). A formação continuada dos profissionais de ensino [Resumo]. Em Unesp, Anais do III Congresso Estadual Paulista sobre a Formação de Educadores (pp. 19-25). São Paulo: Unesp.

García, C. M. (1999). Formação de professores: Para uma mudança educativa. Porto: Porto Editora.

Glat, R. (1999). Uma professora muito especial. Questões atuais em educação especial. Rio de Janeiro: Viveiro de Castro Editores.

Guijarro, R. B. (Org.). (1992). Alumnos con necesidades educativas especiales y adaptaciones curriculares. España: Ministerio de Educación y Ciencia.

Kassar, M. de C. M. (1999). Deficiência múltipla e educação no Brasil: Discurso e silêncio na história dos sujeitos. Campinas: Autores Associados.

Laranjeira, M. I. (2000). Da arte de ensinar ao ofício de aprender - Relato, em reflexão, de uma trajetória. Bauru: EDUSC.

Leite, L. P.(1997). Estudo de estratégias para a formação continuada do professor de educação especial. Dissertação de Mestrado, Universidade Estadual Paulista, Marília.

Libâneo, J. C. (2001). Adeus professor, adeus professora: Novas exigências educacionais e profissão docente. São Paulo: Cortez.

Majón, D. G., Gil, J. R. \& Garrido, A. A. (1995). Adaptaciones curriculares - guía para su elaboración. Granada-España: Aljibe. Colección: Educación para la diversidad. 
Martins, J. (2000). A pesquisa qualitativa. Em I. Fazenda (Org.), Metodologia da pesquisa educacional (6 ${ }^{\mathrm{a}}$ ed., pp. 47-58), São Paulo: Cortez.

Mazzilli, S. \& Muramoto, H. M. S. (1998). Educação continuada e avaliação: Duas faces da mesma moeda. Em Unesp (Org.), V Congresso Estadual Paulista sobre Formação de Educadores, GT 5. Águas de São Pedro. Textos geradores e resumos. (pp. 75-91). São Paulo: Unesp.

Mazzotta, M. J. S. (1996). Educação especial no Brasil: História e políticas públicas. São Paulo: Cortez.

Nogueira, A. L. H. (1993). Eu leio, ele lê, nós lemos: Processos de negociação na construção da leitura. Em M. C. R. Góes \& A. L. B. Smolka (Orgs.), A linguagem do outro no espaço escolar (pp. 15-34). Campinas: Papirus.

Oliveira, A. A. S. (2002). Representações sociais sobre a educação especial e deficiência: O ponto de vista de alunos e professores. Tese em Educação, Universidade Estadual Paulista, Marília.

Oliveira, L. (1997). A ação-investigação e o desenvolvimento profissional dos professores: um estudo no âmbito da formação contínua. Em I. Sá-Chaves (Org.), Percursos de formação $e$ desenvolvimento profissional (pp. 91-106). Lisboa: Editora Porto.

Oliveira, M. K. (1995). Pensar a Educação: Contribuições de Vygotsky. Em J. A. Castorina, E. Ferreiro, D. Lerner \& M. K. Oliveira. Piaget-Vygotsky: Novas contribuições para o debate (pp. 51-84). São Paulo: Ática.

Padilha, A. M. L. (1997). Possibilidades de história ao contrário. Ou como desencaminhar o aluno da classe especial. São Paulo: Plexus.

Padilha, A. M. L. (2001). Práticas pedagógicas na educação especial: A capacidade de significar o mundo e a inserção cultural do deficiente mental. Campinas: Autores Associados.

Pinto, N. B. (1999). Erro: Uma estratégia para a diferenciação do ensino. Em M. André (Org.), Pedagogia das diferenças na sala de aula (pp. 47-80). Campinas: Papirus.

Prada, L. E. A. (2001). Formação continuada de professores: Experiências em alguns países. Revista On-line da Biblioteca Prof. Joel Martins, 2(3), 97-116. Retirado em 07/12/2004, http://www.bibli.fae.unicamp.br/revbfe/index.html.

Ruiz, M. J. C. \& Pereja, E. D. (2002). Las adaptaciones curriculares como estrategias de atención a la diversidad. Em J. A. T. Gonzáles \& A. S. Palomino (Orgs.), Educación especial: Centros educativos y profesores ante la diversidad (pp. 171192). España: Ediciones Pirámide.

Sanchez, I. R. (1995). Professores de educação especial. Da formação às práticas educativas. Porto: Porto Editora.

Smolka, A. L. B. (2000). A criança na fase inicial da escrita: A alfabetização como processo discursivo. São Paulo: Cortezl Campinas: Editora da Universidade Estadual de Campinas.

Schön, D. A. (1992). Formar professores como profissionais reflexivos. Em A. Nóvoa (Org.), Os professores e a sua formação (pp. 77-91). Lisboa: Publicações Dom Quixote.

Vygotsky, L. S., Luria, A. R. \& Leontiev, A. N. (1988). Linguagem, desenvolvimento e aprendizagem. São Paulo: Ícone: EDUSP.

Zanotto, M. A. C. (2002). A formação contínua como possibilidade do aprimoramento da ação de problematizar: Análise de uma proposta voltada para professores atuantes em educação especial. Tese de Doutorado, Universidade de São Carlos, São Carlos.

\author{
Recebido em 16.12.2004 \\ Primeira decisão editorial em 04.04.2005 \\ Versão final em 30.05.2005 \\ Aceito em 06.07.2005
}

